\title{
INTENSITY OF STRESS AND SYMPTOMS OF JOB EXHAUSTION AMONG PARAMEDICS IN POLAND
}

\author{
Domagoj Buljan1, Anna Drozd², Marcin Madziala³, Sebastian Aleksandrowicz ${ }^{4}$ \\ ${ }^{1}$ University of J.J. Strossmayer Osijek, Croatia \\ ${ }^{2}$ International Institute of Rescue Research and Education, Poland \\ ${ }^{3}$ Department of Emergency Medicine, Medical University of Warsaw \\ ${ }^{4}$ Polish Society of Disaster Medicine, Poland
}

\begin{abstract}
BACKGROUND: The aim of this article is to show how the features of job exhaustion depend of the amount of work-related stress.

MATERIALS AND METHODS: This research included a randomly selected group of 456 paramedics, aged between 21 and 51, working at hospital emergency departments and in mobile emergency teams. The authors used the Maslach Burnout Inventory Form and Perceived Job Stress Questionnaire Form.

RESULTS: The most important factors influencing general amount of stress in a paramedic's job include as follows: the sense of responsibility; the sense of insecurity impacted with the system of work; and the sense of psychic workload. However, less important factors influencing stress include: unpleasant work conditions; a lack of support; a lack of control; a sense of threat.

CONCLUSIONS: Paramedics are exposed to job exhaustion syndrome which causes a lessening of feeling safe in their work place. The risk factors influencing job exhaustion syndrome include as follows: uncertainty of work system; sense of psychic workload caused by work; poor social contacts causing a lack of assistance from others; a lack of positive motivators in one's job, such as various rewards.
\end{abstract}

KEY WORDS: stress, job exhaustion, paramedic

Disaster Emerg Med J 2016; (1)1: 43-49

\section{INTRODUCTION}

One of general factors influencing people's health as individuals comprises the conditions of work in their profession. This may be understood in two ways. Firstly, when these conditions are good, it becomes a source of life satisfaction. However, when these conditions are bad, they have a negative effect on one's health. The work of paramedics, people who perform medical rescue actions in emergency conditions, is filled with stress. This stress consists of (among other things): responsibility for patient's health and life; working against the clock during medical treatment; and the conditions of paramedic's medical treatment. In many cases, the above-mentioned factors cause a loss of both work and life satisfaction in this professional group. Paramedics who cannot deal with steady emotional stress are ultimately exposed to job exhaustion syndrome.

In recent years, research has been conducted on job exhaustion syndrome, which is the most dangerous result of work-related stress. This problem is especially noticeable in highly developed countries. Research on 1.600 employees in central European countries, shows that $29 \%$ noticed a destructive effect of work activity regarding their state

ADDRESS FOR CORRESPONDENCE:

Marcin Madziala, Department of Emergency Medicine, Medical University of Warsaw, ul. Lindleya 4, 02-005 Warsaw, Poland, e-mail:mmadziala262@gmail.com 
of being and physical/psychological health. Job exhaustion syndrome is a kind of response to steady active emotional and interpersonal stressors. It is often defined as emotional exhaustion syndrome, depersonalization and lower sense of personal accomplishment [1, 2]. Emotional exhaustion syndrome is most often associated with certain professions, especially professions with direct and continuous contact with people [3].

In many publications it has been confirmed that the factors most influencing job exhaustion syndrome are factors related to work place, such as working against the clock, and a lack of (or little) social support $[4,5]$. Hence, paramedics comprise a professional group often exposed to job exhaustion syndrome, occurring in countries where their social and material position is high. Other negative factors related to the workplace are: poor teamwork; low working status and low salaries; significant responsibility causing a serious mental burden; a lack of good work conditions; and poor cooperation with persons requiring medical treatment [6].

In Poland, paramedics as a group have been psychologically examined very little, possibly as a result of the newness of this profession in the job market. The paramedic's profession is very stressful and requires from every human individual high levels of competence, significant knowledge and abilities in many areas, especially medicine. As the paramedic, in his/her profession, is exposed to many factors, it seems appropriate conduct research on the factors causing stress and to determine them. The aim of this article is to show how the features of job exhaustion features depend on the amount of work-related stress.

\section{MATERIALS AND METHODS}

The research was conducted between January and October 2016. The anonymous self-administered survey was mailed to 546 randomly selected paramedics. It included 423 men and 123 women at ages between 21 and 51 . The average age was $29 \pm 5.7$ years. The persons included in the research were paramedics working in hospital emergency departments $(n=240 ; 43.9 \%)$ and in mobile emergency teams ( $n=306 ; 54.0 \%$ ). Individuals working as paramedics had an average period of experience of $5.6 \pm 4.8$ years among units of health care. While 279 persons were high school educated, 267 persons confirmed that are after-grammar school studies educated in emergency medicine.
The methods used to performance this task were:

- The Maslach Burnout Inventory Form, created by Maslach and Jackson, with a Polish adaptation by Pasikowski [7]. This technique is used to identify the level of job exhaustion. The form consists of 22 questions used to describe the psycho-physical state of the person being assessed related to the biological determinants of stress (due to their job - in this case, that of a paramedic). Questions included in this form were divided into 3 categories related to successive aspects of job exhaustion, namely: emotional exhaustion (EE); depersonalization (DEP); and a lack of personal accomplishments (PA). With higher rates on the EE and DEP scales, we can see a higher job exhaustion level. In the case of the PA scale, however, a lower rate causes a higher job exhaustion level.

- Perceived Job Stress Questionnaire Form created by Dudek and [8]. This method allows one to estimate one's sense of subjective stress and determine which stressor factors are especially influencing the person being assessed. The above-method is based on a questionnaire form consisting of 55 questions. The result assigned to the amount of a sense of stress at work is the sum of points scored by the person being assessed in these areas. Higher scores mean a higher sense of stress of the person being assessed.

\section{RESULTS}

In Figure 1 we can see the average rating of respondents obtained by the Perceived Job Stress Questionnaire Form (restricted to standards developed by Dudek et al. [8]).

In the above figure, we may notice that the examined person obtained a global result at an average score level of 103.7. This suggests a generally high amount of stress at work. According to standards (developed by Dudek et al. [8]), a low level is 1-4 sten (65-80), a middle level is 5-6 sten (81-101) and a high level is 7-10 sten $(\geq 102)$. Analysis of the research material allows us to identify the most important factors influencing amount of stress in a paramedic's job. These factors are: a sense of responsibility; a sense of uncertainity of work system and psychic workload sense. Accordingly, less important stressor factors are: unpleasant work conditions; a lack of support; a lack of control; and a sense of threat. Table 1 shows a correlation 


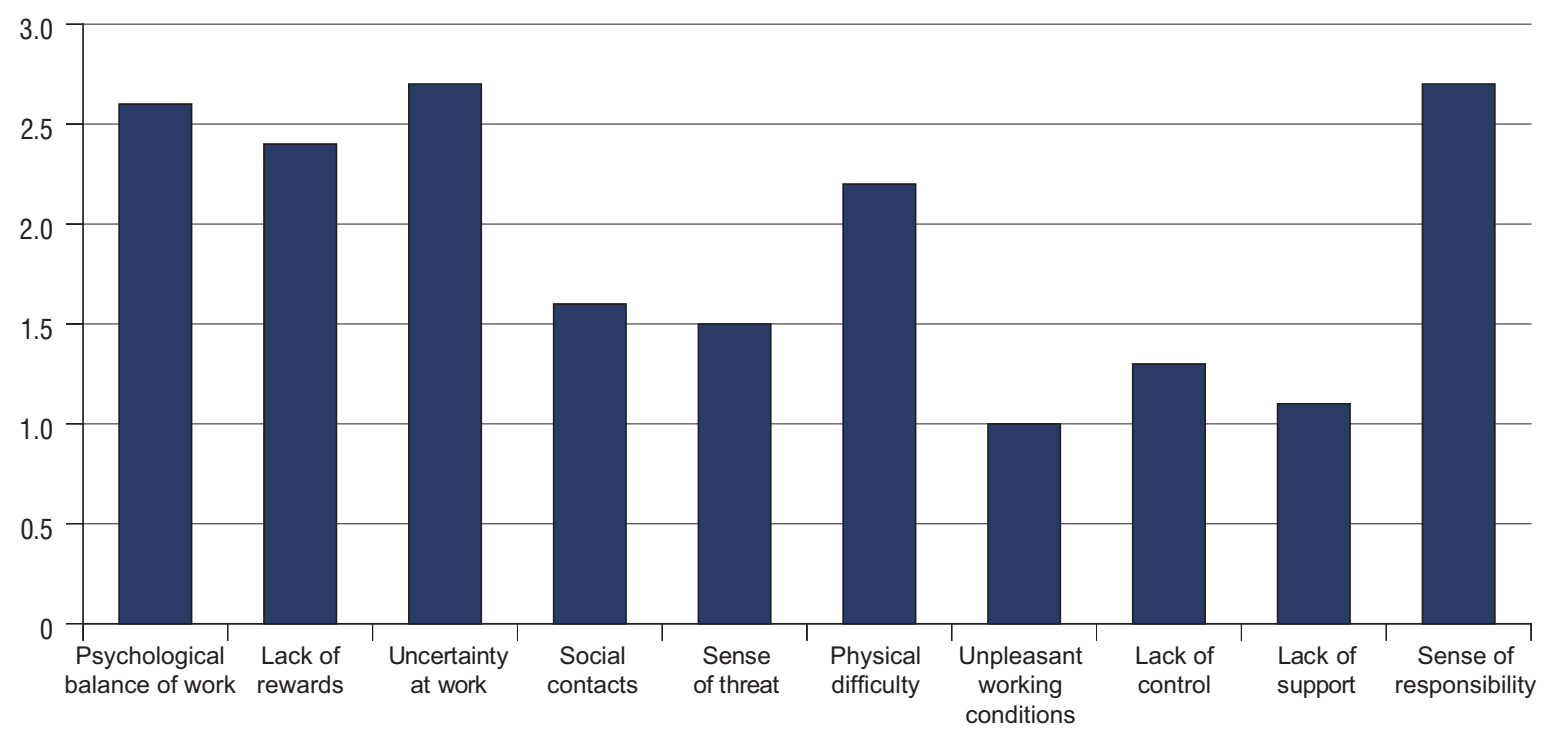

FIGURE 1. Results (mean value) of the Perceived Job Stress Questionnaire obtained in the paramedics' group. The total result amounts to 103.7 points

between the demographic variables of examined paramedics group and the results of the Perceived Job Stress Questionnaire Form.

Analysis shows that there exist statistical important correlations between a sense of threat, physical difficulties, a sense of uncertainty of work system, lack of rewards in job and gender. In the case of men, the sense of a threat factor was more important. In the case of women - physical difficulties, a sense of uncertainity of work system and a lack of rewards. A statistically significant correlation between the age of examined persons and perceived stress was not observed. In the case of the demographic variable (described as "education"), there was significantly correlation between it and factors such as a lack of rewards at work and a lack of support. Important correlations related to the variable "Workplace" were observed in the case of physic workload, a sense of uncertainty of work system, a sense of threat, physical difficulties, unpleasant working conditions and a lack of support. Although a lack of support was more important in cases of hospital emergency department paramedics, the remaining factors were more important in mobile paramedic teams.

In Figure 2 we can see results of the Maslach Burnout Inventory Form obtained from the group of paramedics being assessed. The highest rates may

\section{Table 1. Coefficients of correlation between demographic variables and the Perceived Job Stress Questionnaire}

\begin{tabular}{|l|c|c|c|c|}
\hline \multicolumn{1}{|c|}{ Perceived Job Stress Questionnaire } & Gender & Age & Education & Work place \\
\hline Global stress at work & 0.12 & -0.08 & -0.17 & -0.14 \\
\hline Psychological balance at work & 0.09 & -0.02 & -0.03 & $0.24^{*}$ \\
\hline Lack of rewards & $0.26^{*}$ & -0.02 & $-0.29^{*}$ & 0.08 \\
\hline Uncertainty at work & $0.21^{*}$ & -0.16 & 0.07 & $0.22^{*}$ \\
\hline Social contacts & 0.13 & -0.05 & 0.1 & -0.19 \\
\hline Sense of threat & $-0.25^{*}$ & 0.06 & -0.09 & $0.25^{*}$ \\
\hline Physical difficulty & $0.29^{*}$ & -0.012 & -0.12 & $0.26^{*}$ \\
\hline Unpleasant working conditions & -0.16 & -0.07 & -0.17 & $0.29^{*}$ \\
\hline Lack of control & 0.06 & 0.03 & -0.19 & 0.08 \\
\hline Lack of support & 0.03 & 0.04 & $-0.23^{*}$ & $-0.28^{*}$ \\
\hline Sense of responsibility & 0.19 & -0.1 & 0.62 & 0.50 \\
\hline
\end{tabular}

${ }^{*} p<0.005$ 
be seen on the sense of personal accomplishments scale. Although the results of the emotional exhaustion scale displayed average values, the results of the depersonalization scale had lower values. Related to the lack of standards developed in this questionnaire, the obtained results from the group of paramedics were compared with research of other professional groups: fire-fighters $(n=43)$ and nurses $(n=24)$. There is higher level of job exhaustion $(M=15.9)$ in relation to fire-fighters $(M=8.6)$ and nurses $(M=11.0)$. The sense of personal accomplishment in the group of paramedics $(M=26.6)$ is comparable to nurses $(M=27.03)$ but lower than fire-fighters $(M=29.67)$.

Table 2 shows a correlation between the Maslach Burnout Inventory Form results (MBI) and the demographic variables of tested paramedics. No important correlations between gender, age and job exhaustion factors were observed. A lower level of emotional exhaustion and a higher sense of personal accomplishment were related to those with higher education. In the case of paramedics working with mobile teams, there was higher depersonalization level than among hospital emergency department

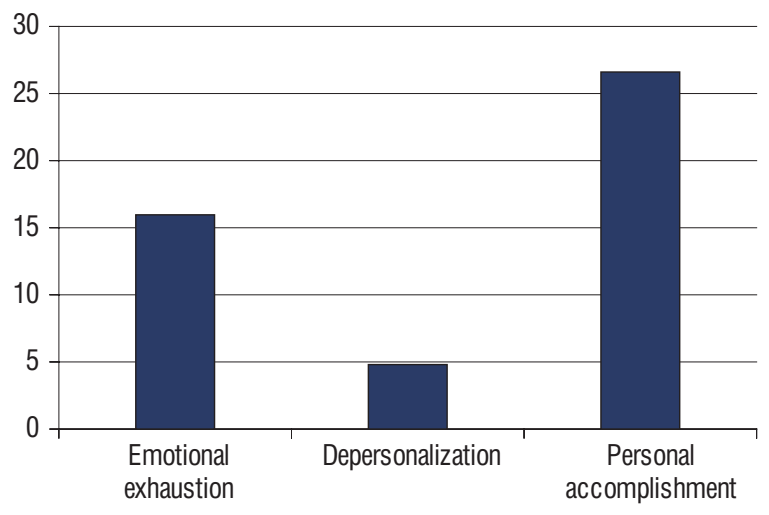

FIGURE 2. The results (mean value) in the Maslach Burnout Inventory (MBI) obtained in the paramedics' group

employees. Table 3 shows a correlation between job exhaustion and sense of stress at work and its factors.

According to the results above, we can observe that, in the examined group of paramedics, a higher level of job exhaustion correlates with a higher amount of stress at work, a lack of rewards, a higher sense of psychic workload, sense of uncertainty of work system, discomfort caused by the need of keeping social contacts, a sense of threat and

\begin{tabular}{|l|c|c|c|c|}
\hline \multicolumn{6}{|c|}{ Table 2. Coefficients of correlation between demographic variables and Maslach Burnout Inventory (MBI) } \\
\hline \multicolumn{1}{|c|}{ Maslach Burnout Inventory (MBI) } & Gender & Age & Education & Work place \\
\hline Emotional exhaustion & 0.3 & -0.12 & $-0.26^{*}$ & -0.09 \\
\hline Depersonalization & -0.04 & -0.14 & -0.15 & $0.3^{*}$ \\
\hline Personal accomplishment & 0.2 & 0.01 & $0.31^{*}$ & 0.27 \\
\hline
\end{tabular}

${ }^{*} p<0.001$

\begin{tabular}{|c|c|c|c|}
\hline \multirow{2}{*}{ Perceived Job Stress Questionnaire } & \multicolumn{3}{|c|}{ Maslach Burnout Inventory (MBI) } \\
\hline & Emotional exhaustion & Depersonalization & Personal accomplishment \\
\hline Global stress at work & $0.43^{* *}$ & $0.36^{* *}$ & $-0.32^{*}$ \\
\hline Psychological balance at work & $0.37 * *$ & $0.39 * *$ & -0.12 \\
\hline Lack of rewards & $0.49 * *$ & $0.27^{*}$ & $-0.3^{* *}$ \\
\hline Uncertainty at work & $0.5^{*}$ & $0.29 *$ & $-0.29 *$ \\
\hline Social contacts & 0.09 & 0.19 & -0.13 \\
\hline Sense of threat & $0.25^{*}$ & 0.23 & 0.05 \\
\hline Physical difficulty & 0.08 & 0.17 & 0.12 \\
\hline Unpleasant working conditions & 0.19 & 0.12 & -0.04 \\
\hline Lack of control & 0.11 & 0.16 & -0.11 \\
\hline Lack of support & 0.17 & $0.28^{*}$ & -0.18 \\
\hline Sense of responsibility & $0.36^{*}$ & 0.13 & $0.27^{* *}$ \\
\hline
\end{tabular}

${ }^{*} p<0.05 ;{ }^{* *} p<0.01$ 
a sense of personal responsibility. A higher depersonalization coefficient related to the following factors: a global sense of stress at work, psychic workload sense, a lack of rewards, sense of uncertainty of work system and a lack of support. The final coefficient - a sense of personal accomplishment - caused a lower sense of a lack of rewards at work, a lower sense of global stress at work, a lower sense of uncertainty of work system and higher sense of responsibility.

\section{DISCUSSION}

Workplace stress has a negative impact on the health and functioning of employees. This hypothesis seems to have been confirmed by the Misra [9] and Regehr research teams [10]. These studies have shown that among paramedics, stress seriously disorganizes their work. However we have to remember that paramedic can be exposed to malaise and psychological diseases [11]. Due to their job, paramedics, similar to nurses, are especially exposed to the loss of job and general life satisfaction $[9,12]$. One of the research concepts explaining the formation of stressful situations at the workplace shows that these situations appear when there is a disparity between the requirements needed from employees and their personal capabilities to meet these needs. Subsequently, having a stressful job influences one's exhaustion which reveals itself as worse psychomotor coordination, as well as malaise, thereby increasing mental tension and the weakness of the emotional reactions of the person concerned. Stress reactions - excluding psychological changes - cause disturbances within the body, including neurotic syndromes. Thus, the demands needed from paramedics are burdening both their physical and mental health [9].

The examined group of paramedics was characterized by high level of stress at work $(M=103,7)$. The group above had the highest results at on the following subscales: a sense of responsibility; sense of uncertainty of work system; sense of psychic workload; and a lack of rewards at work. An interpretation of Figure 1 may mean that a sense of abnormal workload, a sense of abnormal responsibility, sense of uncertainty of work system and interpersonal problems with co-workers - while there is a lack of very little positive stimulation in the form of rewards - comprise the most stressful factors at work of the group of employees being assessed.
Regarding analysis of the MBI questionnaire, paramedics obtained the highest scores at scale of personal accomplishment due to the results of emotional exhaustion and depersonalization scales. These results are consistent with the results of other authors [13-16]. The examined group of paramedics was compared with a group of nurses and fire-fighters regarding job exhaustion. This group was characterized by a higher level of job exhaustion, accordingly to fire-fighters' group, as well as the nurses' group. The depersonalization level was comparable with fire-fighters but lower than nurses. The level of a sense of personal accomplishment was, however, comparable with the nurses' group, but lower than the fire-fighters' group. These results shows, that examined group of paramedics is more exposed to job exhaustion than either fire-fighters or nurses.

The data presented in Table 1 show that there is an important relationship between selected stressor factors and gender. As is clear from the research, for men the greatest stressor factor was a sense of threat while for women this comprised a lack of positive stimulations in the form of rewards at work, sense of uncertainty of work system, as well as physic loads caused by their job. However, a relationship between the ages of the examined respondents and perceived stress was not observed. There was visible significant relationship between education and two workplace factors, namely a lack of support and a lack of rewards at work. In the examined group, those with a lower educational status (e.g. after-grammar school studies) needed more positive stimulation (e.g. financial gratification), as well as support from co-workers which would allow them not feel a stressful work situation compared to those with higher education (high school). The situation described above may be related to greater dependence on one's environment and lower self-esteem in people with lower-level education. Most of the correlations were noticed to relate to the workplace demographic variable. Although a lack of support was more visible in the case of persons working at hospital emergency departments, a sense of psychic workload, uncertainty of work system, a sense of threat, physical difficulties, unpleasant working conditions and a lack of support were more important in the case of those working in mobile teams of paramedics. This may be associated with the necessity of working in an environment of extreme conditions, working against the clock and having responsibility for the patient's life, as it is in the case 
of mobile paramedics. When this is compared to those working in hospital emergency departments where one may always ask for the help a doctor or a nurse, the paramedic here is not left on their own.

Accordingly to Table 2, where the correlation coefficients between demographic variables and the $\mathrm{MBI}$ questionnaire results are shown, we may conclude that an important correlation between job exhaustion and demographic variables appears only in combination of emotional exhaustion and sense of personal accomplishments, as well as education and depersonalization related to the workplace. The obtained results show that people with lower education react in an emotionally exhausted manner to various stressors, as well feeling tired and not seeing opportunities to better improve their position. In the case of highly educated people, they are capable of personal accomplishments and less prone to job exhaustion. The key element due to depersonalization is the workplace. Accordingly to our own research, we may conclude that in the examined group, a higher level of depersonalization - which is related to a higher capability of job exhaustion syndrome - is affecting people working in mobile paramedics teams. These results just confirm research conducted by Thorsen and [16], Surgenor and [15], as well as Lazzari and [14].

Analysis of the research material shown in Tab. 3 indicates a correlation between a sense of stress and job exhaustion in the group of examined paramedics. It was observed that with higher levels of perceived stress on the above-mentioned subscales of the Perceived Job Stress Questionnaire, there is higher amount of job exhaustion syndrome symptoms on the MBI questionnaire. Those who had lower emotional exhaustion levels had less experience of a lack of positive stimulation at work, had a lower sense of general stress at work, had a lower sense of psychic workload and better social contacts.

Those with symptoms of depersonalization, similar those with symptoms of job exhaustion, had a significantly increased sense of general stress at work, as well as psychic workload. They were also more sensitive to a lack of positive stimulation, such as lack of rewards at work, and more sensitive to any changes caused by the system of work. Such individuals were characterized by an increased need for support and a sense of a lack of control of their emotions. Although in the case of people with a high sense of personal accomplishment work-related stress was felt less, they were characterized with a lower sensitivity to uncertainties connected with the system of work and less dependence on rewards at work. In the examined group of paramedics, the strongest correlation was shown between the amount of job exhaustion and sense of global stress at work, uncertainty of work system, lack of rewards at work and psychic load at work. The results obtained from this research are consistent with the results of other authors, both Polish and foreign $[17,18]$.

Visser et al. [19] also showed a relationship between the degree of the amount of traits of job exhaustion syndrome and a sense of excessive workload - stress [19]. The results obtained indicate a direct relationship between job satisfaction, stress levels and job exhaustion syndrome. Moreover, research on nurses and doctors has confirmed a positive relationship between stress felt at work and job exhaustion syndrome. In summary, it should be noted that the impact of stress on the health of the employees, in this case paramedics, is undisputed, as confirmed by research. People subjected to the long-duration action of stressor factors experience strong psychological discomfort and have a higher risk of mental and psychosomatic disorders [19, 20]. Therefore, one may assume that the prevention of job exhaustion syndrome can have a positive impact on employees, which will affect the quality of health services provided.

\section{CONCLUSSIONS}

Paramedics are at risk of job exhaustion syndrome, which contributes to reducing the sense of certainty in the workplace.

The risk factors affecting job exhaustion syndrome occurrence are: uncertainty of work system, a sense of psychic workload, worse social contacts impacted by a lack of support from other people; and a lack of positive stimulation at work, such as various rewards.

Conflict of interest: None declared.

\section{REFERENCES}

1. Paoli P. Second European Survey on the Work Environment 1995. European Foundation for the Improvement of Living and Working Conditions, Loughlinstown House, Dublin 1997.

2. Lasalvia A, Tansella M. Occupational stress and job burnout in mental health. Epidemiol Psychiatr Sci, 2011; 20(4): 279-85. 
3. Wright JG, Khetani N, Stephens D. Burnout among faculty physicians in an academic health science centre. Paediatr Child Health, 2011; 16(7): 409-413.

4. Weber A, Jaekel-Reinhard A. Burnout syndrome: a disease of modern societies?, Occup Med Lond, 2000; 50(7): 512-517.

5. Backovic $D$, Jevtic M. Burnout syndrome as a mental health problem among medical students. Med Pregl, 2012; 65(3-4): 129-132.

6. Pinces A. Wypalenie w perspektywie egzystencjonalnej. In: Sek H (red.). Wypalenie zawodowe. Przyczyny, mechanizmy, zapobiegnie. PWN, Warszawa 2000: 32-58.

7. Pasikowski T. Stres i zdrowie. Fundacja Humaniora, Poznań 2000.

8. Dudek B, Waszkowska M, Hanke W. Ochrona zdrowia pracowników przed negatywnymi skutkami stresu zawodowego. Instytut Medycyny Pracy, Łódź 1999.

9. Misra M, Greenberg N, Hutchinson C, Brain A, Glozier N. Psychological impact upon London Ambulance Service of the 2005 bombings. Occup Med (Lond), 2009; 59(6): 428-433.

10. Regehr C, Goldberg G, Hughes J. Exposure to human tragedy, empathy, and trauma in ambulance paramedics. Am J Orthopsychiatry, 2002; 72(4): 505-513.

11. Anagnostopoulos F, Liolios E, Persefonis G, Slater J, Kafetsios K, Niakas D. Physician Burnout and Patient Satisfaction with Consultation in Primary Health Care Settings: Evidence of Relationships from a onewith-many Design. J Clin Psychol Med Settings, 2012; 19(4): 401-410.

12. Leczyńska A. Konsekwencje wypalenia. Magazyn pielęgniarki i położnej, 2007; 3: 22-23.
13. Deneckere S, Euwema M, Lodewijckx C et al. Better Interprofessional Teamwork, Higher Level of Organized Care, and Lower Risk of Burnout in Acute Health Care Teams Using Care Pathways: A Cluster Randomized Controlled Trial. Med Care, 2013; 51(1): 99-107.

14. Lazzari D, Pisanti R, Avallone F. Perception of organizational climate and burnout amongst health care workers: the role of alexithymia as a moderator. G Ital Med Lav Ergon, 2006; 28(1): 43-48.

15. Surgenor $\sqcup$ et al. Burnout in hospital-based medical consultants in the New Zealand public health system. NZ Med J, 2009; 122(1300): 11-18.

16. Thorsen VC, Tharp AL, Meguid T. High rates of burnout among maternal health staff at a referral hospital in Malawi: A cross-sectional study. BMC Nurs, 2011; 10: 9.

17. Maslach C. Wypalenie — w perspektywie wielowymiarowej. In: Sek $\mathrm{H}$ (red.). Wypalenie zawodowe. Przyczyny i zapobieganie, Warszawa 2006, 13-32.

18. Ogińska-Bulik N. Zasoby osobiste chroniące funkcjonariuszy policji przed negatywnymi skutkami stresu zawodowego. In: Juczyński Z, Ogińska-Bulik N (red.). Zasoby osobiste i społeczne sprzyjające zdrowiu jednostki. Uniwersytet Łódzki, Łódź 2003: 91-102.

19. Visser MR, Smets EM, Oort FJ, De Haes HC. Stress, satisfaction and burnout among Dutch medical specialists. CMAJ, 2003; 168(3): 271-275.

20. Ahola K, Hakanen J. Burnout among health care professionals. Duodecim, 2010; 126(18): 2139-2146. 